\title{
Desenvolvimento de biomaterial composto por hidroxiapatita e clorexidina para aplicação na cavidade oral
}

\section{(Development of a biomaterial made by hydroxyapatite and chlorhexidine for application to the oral cavity)}

\author{
M. V. B. dos Santos ${ }^{1}$, G. T. Feitosa ${ }^{1}$, J. A. Osajima ${ }^{1}$, R. L. P. Santos ${ }^{1}$, E. C. da Silva Filho ${ }^{1 *}$ \\ ${ }^{I}$ Universidade Federal do Piauí, Centro de Tecnologia, Laboratório Interdisciplinar de Materiais Avançados, \\ Teresina, PI, Brasil
}

Resumo

\begin{abstract}
A hidroxiapatita (HAp) está presente no organismo humano nos tecidos ósseos e dentários, em que do total da massa de cada tecido 30 a 70\% correspondem a HAp, podendo ser aplicada como revestimentos de próteses ou até substituição de pequenas partes ósseas. Assim, o objetivo foi sintetizar HAp por precipitação, incorporar clorexidina (CHX) e avaliar as propriedades microbianas. A caracterização foi realizada por DRX, FTIR, TG/DTG, MET e MEV. A CHX foi incorporada à HAp por adsorção, variando a quantidade incorporada. O difratograma apresentou picos em $25,9^{\circ}, 31,5^{\circ}, 32,2^{\circ}$ e $32,7^{\circ}(2 \theta)$ referentes aos planos $(002)$, (211), (112) e (300) da HAp. O espectro de FTIR mostrou banda em $1050 \mathrm{~cm}^{-1}$ correspondente à deformação dos grupos fosfatos e deformações de grupos $\mathrm{CH}_{2}$ em 1485 e $1445 \mathrm{~cm}^{-1}$ da clorexidina, que apresentou morfologia porosa e cilíndrica. O biomaterial apresentou excelentes propriedades antimicrobianas frente a Streptococcus mutans, Staphylococcus aureus e Escherichia coli. Palavras-chave: hidroxiapatita, clorexidina, atividade antimicrobiana.
\end{abstract}

Abstract

Hydroxyapatite (HAp) is present in the human body in bone and dental tissues, which of the total mass of each tissue 30 to $70 \%$ correspond to HAp, and can be applied as coatings of prostheses or replacement of small bone parts. Thus, the objective was to synthesize HAp by precipitation, to incorporate chlorhexidine (CHX) and to evaluate the microbial properties. The characterization was performed by XRD, FTIR, TG/DTG, TEM and SEM. CHX was incorporated into the HAp by adsorption, varying the amount

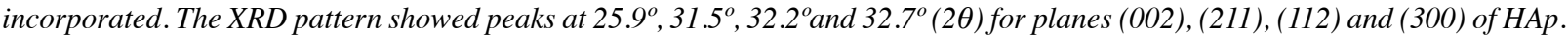
The FTIR spectrum showed band at $1050 \mathrm{~cm}^{-1}$ corresponding to the deformation of the phosphate groups and deformations of $\mathrm{CH}_{2}$ groups at 1485 and $1445 \mathrm{~cm}^{-1}$ of chlorhexidine, which presented porous and cylindrical morphology. The biomaterial showed excellent antimicrobial properties against Streptococcus mutans, Staphylococcus aureus and Escherichia coli.

Keywords: hydroxyapatite, chlorhexidine, antimicrobial activity.

\section{INTRODUÇÃO}

Os avanços tecnológicos alcançados pelo homem trazem em si características que demonstram as necessidades vividas pelas sociedades em cada época. Como tecnologia da área da saúde, pode-se citar o desenvolvimento dos biomateriais [1-4], que são materiais que devem apresentar um conjunto de propriedades físicas, biológicas e químicas que permitem a estes desempenharem função de auxílio ou de substituição de partes do corpo dos seres vivos sem deixar de estimular uma resposta adequada dos tecidos [5, 6]. Os biomateriais apresentam propriedades físicas, químicas e biológicas bem específicas que inibem a rejeição e que podem até estimular os tecidos vivos aos quais estão ligados [3,7]. Biovidros, alumina, beta fosfato tricálcico ( $\beta$-TCP), octafosfato de cálcio

*edsonfilho@ufpi.edu.br

(D) https://orcid.org/0000-0003-0988-2970
(OCP) e a hidroxiapatita (HAp) são exemplos de materiais cerâmicos utilizados nas pesquisas com biomateriais, sendo bastante usados na área médica-odontológica [8]. A HAp é um fosfato de cálcio largamente utilizado como biomaterial em aplicações médicas, tais como revestimento de próteses, substituições de pequenas partes ósseas e sistema de entrega de drogas $[9,10]$. Essas aplicações são permitidas devido à HAp ser um componente natural do organismo, estando presentes em dentes e ossos com uma porcentagem de 30 a $70 \%$ em massa total destes tecidos. A similaridade química da HAp com o tecido ósseo e dentário garante a excelente biocompatibilidade, bioatividade, ausência de toxicidade e propriedade osteocondutiva, proporcionando poros que indicam o caminho para o crescimento ósseo $[4,5]$.

Aliada às características de biocompatibilidade, bioatividade, presença de poros, entre outras já citadas, a incorporação da clorexidina (CHX) na HAp proporciona o desenvolvimento de um biomaterial com excelente ação 
quando aplicado como agente antimicrobiano. A CHX é um detergente catiônico da classe das bisbiguanidas e que pode ser encontrada no mercado na forma de acetato, hidrocloreto e digluconato, sendo este último a forma mais encontrada. A CHX possui um vasto campo de atuação agindo contra bactérias gram-positivas, bactérias gram-negativas, fungos, leveduras e vírus lipofílico [11]. A solução de CHX na concentração de $0,12 \%$ é bastante utilizada na cavidade oral, porém com um efeito passageiro, especialmente pela renovação constante da saliva e do muco [12]. A CHX em altas concentrações é bactericida, causando o extravasamento dos constituintes celulares de baixa massa molecular e a precipitação do conteúdo intracelular; já em baixas concentrações, torna-se bacteriostática [13]. O grande desafio terapêutico é conseguir um sistema antimicrobiano eficaz que mantenha a concentração inibitória mínima por um determinado período de tempo e reduza a incidência da infecção e de efeitos adversos [14]. Uma reflexão sobre a sentença anterior induzà ideia de se buscar um biomaterial que contribua na recuperação do tecido dentário e que apresente um efeito terapêutico desejado contra agentes microbianos na mucosa oral, o que instiga a se pensar na incorporação de CHX na HAp para aplicação na odontologia. Dessa forma, este trabalho teve por objetivo sintetizar hidroxiapatita por precipitação, seguida da incorporação de CHX para aplicações odontológicas voltadas para revestimento de implantes orais e enchimento de pequenas partes da arcada dentária e maxilar. Os materiais (HAp e HAp/CHX) foram caracterizados pelas técnicas de TG/DTG, FTIR, DRX, MEV e MET como também ocorreu a avaliação microbiológica por contato direto frente as linhagens bacterianas Streptococcus mutans, Staphylococcus aureus e Escherichia coli.

\section{EXPERIMENTAL}

Materiais: foram utilizados os reagentes: hidróxido de cálcio, $\mathrm{Ca}(\mathrm{OH})_{2}$ (Isofar); fosfato de amônio dibásico, $\left(\mathrm{NH}_{4}\right)_{2} \mathrm{HPO}_{4}$ (Vetec); clorexidina, $\mathrm{C}_{22} \mathrm{H}_{30} \mathrm{Cl}_{2} \mathrm{~N}_{10}$, a $20 \%$ (Polyorganic); blood agar base (Columbia); e água destilada. Todos os reagentes foram utilizados sem tratamento prévio.

Sintese da hidroxiapatita: a HAp foi obtida através do método de precipitação, um método simples e fácil de ser executado. $\mathrm{O}$ procedimento da síntese aconteceu pela dissolução de 1,4750 e 1,5775 g dos reagentes precursores de cálcio $\left[\mathrm{Ca}^{2+}, \mathrm{Ca}(\mathrm{OH})_{2}\right]$ e fosfato $\left[\mathrm{PO}_{4}^{2-},\left(\mathrm{NH}_{4}\right)_{2} \mathrm{HPO}_{4}\right]$, respectivamente, em água destilada, com cada dissolução feita individualmente. Após as dissoluções, as soluções foram misturadas e colocadas em um béquer, com a mistura das soluções passando por um processo de agitação por $4 \mathrm{~h}$ a $25^{\circ} \mathrm{C}$. Após a agitação, a HAp foi precipitada por centrifugação a $4000 \mathrm{rpm}$ por $2 \mathrm{~min}$, desprezando-se o sobrenadante, seguida da lavagem da HAp com água destilada, centrifugação e o descarte do sobrenadante. O procedimento de lavagem da HAp sintetizada foi repetido três vezes. Posteriormente a HAp foi seca em estufa a 100 ${ }^{\circ} \mathrm{C}$ por $24 \mathrm{~h}$. A finalização do processo de síntese de HAp foi feita pelo processo de desaglomeração do pó obtido por meio de trituração do material.

Incorporação da clorexidina na hidroxiapatita: a incorporação de CHX na HAp foi executada através do processo de adsorção na interface sólido-líquido. Esse processo se desenvolveu com o preparo de soluções diluídas a partir da solução de CHX a 20\%, concentração disponível no comércio. O preparo das soluções se deu com a utilização de um balão volumétrico de $50 \mathrm{~mL}$, onde para o biomaterial 1 , por exemplo, foram adicionados $0,5 \mathrm{~mL}$ de solução de CHX comercial e 49,5 mL de água destilada. Os volumes de CHX utilizados para preparo da solução de incorporação e os valores das concentrações de incorporação após as diluições estão dispostos na Tabela I. A incorporação ocorreu utilizando-se erlenmeyers, sendo adicionados a estes $1,0 \mathrm{~g}$ de HAp e em seguida $25 \mathrm{~mL}$ de cada uma das soluções descritas na Tabela I, com agitação orbital por $24 \mathrm{~h}$ em $150 \mathrm{rpm}$ a $25^{\circ} \mathrm{C}$. A solução do sobrenadante foi separada por filtração e quantificada através de espectrômetro UV-vis $(\lambda=255 \mathrm{~nm})$, ocorrendo a determinação do valor da concentração final das soluções através da Eq. A:

$$
\mathrm{Q}_{\mathrm{e}}=\frac{\left(\mathrm{C}_{1}-\mathrm{C}_{2}\right) \cdot \mathrm{V}}{\mathrm{m}}
$$

sendo $\mathrm{Q}_{\mathrm{e}}$ a quantidade de CHX incorporada na HAp em $\mathrm{mg} / \mathrm{g}, \mathrm{C}_{1}$ a concentração inicial da solução de CHX em $\mathrm{mg} / \mathrm{L}, \mathrm{C}_{2}$ a concentração do sobrenadante em $\mathrm{mg} / \mathrm{L}$, V é o volume que foi utilizado no teste de adsorção (L) e m é a massa de HAp que foi utilizada no teste de adsorção (g). A recuperação do pó se deu pelo processo de filtração simples, onde a HAp/CHX ficou retida no papel de filtro. O pó obtido foi seco em estufa por $1 \mathrm{~h} \mathrm{a} 50^{\circ} \mathrm{C}$.

Testes microbiológicos. Cepas bacterianas: os testes antibacterianos dos biomateriais sintetizados tiveram sua ação testada contra cepas de Streptococcus mutans, Staphylococcus aureus e Escherichia coli multirresistentes

Tabela I - Concentração e volume de CHX utilizado no preparo da solução para incorporação na HAp.

[Table I - Concentration and volume of CHX used in the preparation of solution for HAp incorporation.]

\begin{tabular}{ccc}
\hline HAp/CHX & $\begin{array}{c}\text { Concentração de } \\
\text { incorporação (\%) }\end{array}$ & $\begin{array}{c}\text { Volume de } \\
\text { CHX (mL) }\end{array}$ \\
\hline HAp/CHX1 & 0,2 & 0,50 \\
HAp/CHX2 & 0,5 & 1,25 \\
HAp/CHX3 & 1,0 & 2,50 \\
HAp/CHX4 & 2,0 & 5,00 \\
HAp/CHX5 & 4,0 & 10,00 \\
HAp/CHX6 & 6,0 & 15,00 \\
HAp/CHX7 & 11,0 & 27,50 \\
HAp/CHX8 & 14,0 & 35,00 \\
HAp/CHX9 & 17,0 & 42,50 \\
HAp/CHX10 & 20,0 & 50,00 \\
\hline
\end{tabular}


às drogas de origem clínica. As cepas de Staphylococcus aureus e Escherichia coli foram mantidas em ágar nutriente a $4^{\circ} \mathrm{C}$. Preparo do inóculo: as culturas bacterianas das espécies Staphylococcus aureus, Escherichia coli e Streptococcus mutans foram obtidas a partir da transferência de uma alçada do crescimento bacteriano em ágar nutriente para um tubo falcon contendo $3,0 \mathrm{~mL}$ do meio brain heart infusion (BHI), seguido de incubação a $37{ }^{\circ} \mathrm{C}$ por $24 \mathrm{~h}$, sendo a última produzida em atmosfera rica em $\mathrm{CO}_{2}$. Teste de contato direto: o teste antimicrobiano utilizado foi o contato direto, tendo como resultado a contagem de unidade formadora de colônias (UFC). O meio de crescimento utilizado foi o BAB (blood agar base). A preparação do meio de crescimento deu-se pela hidratação de $44 \mathrm{~g}$ do meio por $1000 \mathrm{~mL}$ de água destilada. A solução de BAB foi aquecida até ocorrer toda a dissolução do meio, em seguida foi levada à autoclave, onde permaneceu a $121^{\circ} \mathrm{C}$ por $15 \mathrm{~min}$. Em seguida ocorreu o plaqueamento, partindo-se para o teste de esterilidade em estufa microbiológica por $24 \mathrm{~h}$. O teste do contato direto partiu da mistura de $2000 \mu \mathrm{L}$ do inóculo de concentração de $10^{-4} \mathrm{UFC} / \mathrm{mL}$ das cepas bacterianas e aproximadamente $2000 \mu \mathrm{g}$ de HAp/CHX. Da mistura foram recolhidos 200 $\mu \mathrm{L}$ que foram espalhados verticalmente, horizontalmente e diagonalmente sobre o meio de crescimento com auxílio da alça de Drigalski. Levou-se a placa para a estufa microbiológica, deixando-a em repouso por $24 \mathrm{~h}$, onde em seguida se fez a contagem das unidades formadoras de colônia (UFC). O teste foi feito em triplicata para cada uma das dez concentrações diferentes de CHX que foram incorporadas na HAp. Controles positivos de crescimento bacteriano (solução salina) e controles negativos (CHX pura) foram preparados para as comparações nos testes. Os testes foram realizados segundo metodologia de Zheng e Zhu [15]. O cálculo para o efeito inibitório apresentado pelos biomateriais HAp/CHX foi dado de acordo com a Eq. B:

$$
\eta_{\mathrm{e}}=\frac{\mathrm{N}_{1}-\mathrm{N}_{2}}{\mathrm{~N}_{1}} \cdot 100 \%
$$

onde $\eta$ é definido como efeito inibitório, $\mathrm{N}_{1}$ é a média aritmética das unidades formadoras de colônias das placas de controle e $\mathrm{N}_{2}$ é a média aritmética das unidades formadoras de colônia de cada um dos biomateriais que foram testados.

Caracterizações: a difração de raios (DRX) foi realizada em um LabX-XDR 600, Shimadzu, CuK $\alpha(\lambda=1,5406 \AA)$ com $2 \theta$ no intervalo de $5^{\circ}$ a $75^{\circ}$, com taxa de varredura de $2^{\circ} \cdot \mathrm{min}^{-1} \mathrm{e}$ tempo de exposição de $40 \mathrm{~min}$. Os tamanhos dos cristalitos foram calculados por meio de:

$$
\mathrm{t}_{\mathrm{c}}=\frac{0,9 . \lambda}{\beta \cos \theta}
$$

onde $\mathrm{t}_{\mathrm{c}}$ é o tamanho do cristalito (nm), $\lambda$ é o comprimento de onda para a radiação $\mathrm{CuK} \alpha, \beta$ é a largura a meia altura do pico de difração em consideração (rad) e $\theta$ é o ângulo de difração (grau). A espectroscopia de infravermelho com transformada de Fourier (FTIR) foi realizada em um espectrômetro (Vertex 70, Brucker Optics) com 128 varreduras para cada amostra preparada com pastilha de $\mathrm{KBr}$. A análise térmica foi executada no equipamento SDT Q600 V20.9 Build 20 da TA Instruments, em atmosfera de nitrogênio com fluxo de $100 \mathrm{~mL} / \mathrm{min}$ e taxa de aquecimento de $10^{\circ} \mathrm{C} / \mathrm{min}$. Para as análises de microscopia eletrônica de varredura (MEV), as amostras foram depositadas em fitas de carbono sobre suportes de alumínio. Após metalização com ouro, as micrografias foram coletadas usando elétrons secundários em um microscópio Jeol 6360 LV, operado em $15 \mathrm{kV}$. Já para as análises por microscopia eletrônica de transmissão (MET), as amostras foram suspensas em álcool isopropílico, sonicadas e depositadas sobre um filme fino de carbono, este previamente depositado sobre uma grade de cobre. O microscópio utilizado foi o Jeol JEM 2100F com tensão de aceleração de $200 \mathrm{kV}$ e canhão de emissão de campo (FEG).

\section{RESULTADOS E DISCUSSÃO}

Caracterização da hidroxiapatita e dos biomateriais: os difratogramas de raios $\mathrm{X}$ da HAp sintetizada pelo método de precipitação simples e do biomaterial HAp/CHX10 preparado pela incorporação do fármaco estão apresentadas na Fig. 1. O difratograma obtido experimentalmente foi comparado ao arquivo cristalográfico JCPDS 00-003-0747, indicando a formação da fase referente à hidroxiapatita. $\mathrm{O}$ pico de maior intensidade foi localizado na posição $2 \theta$ de $31,5^{\circ}$, referente ao plano (211), acompanhado de picos de menor intensidade nas posições $25,9^{\circ}, 32,2^{\circ}$ e $32,7^{\circ}$ referentes aos planos (002), (112) e (300). A indexação destes planos apresentados indicou a existência de uma única fase presente, hidroxiapatita, $\mathrm{Ca}_{10}\left(\mathrm{PO}_{4}\right)_{6}(\mathrm{OH})_{2}$, ao tempo em que também correspondeu à alta cristalinidade do material sintetizado proveniente dos picos bem definidos [16-18]. A comparação entre o difratograma da HAp sintetizada com arquivo cristalográfico correspondente deu sustentação para se afirmar que ocorreu a síntese da fase desejada, HAp. A Tabela II apresenta a comparação dos picos experimentais da HAp, do biomaterial HAp/CHX e os picos do arquivo cristalográfico 00-003-0747, que confirmam essa afirmação. $\mathrm{O}$ fato do difratograma do biomaterial HAp/CHX10 se apresentar da mesma forma que o da HAp pura indicou que a incorporação do fármaco não se deu a nível estrutural da molécula, já que uma modificação estrutural ocasionaria um rearranjo atômico, causando uma mudança nos planos cristalográficos do biomaterial, tornando diferente os difratogramas, fato que não ocorreu. Acerca da cristalinidade, a comparação dos difratogramas da HAp pura e do biomaterial HAp/CHX mostrou que houve uma pequena variação da cristalinidade entre os materiais. Esta variação se mostrou mais aparente quando se compararam os picos na região de $10^{\circ}$ a $22^{\circ}$, mostrando que a incorporação da $\mathrm{CHX}$ na HAp proporcionou apenas uma pequena diminuição da cristalinidade da HAp, mas sem causar nenhuma modificação estrutural; tal justificativa se baseou na diminuição da intensidade do pico e o aumento da largura a meia altura [19]. A Tabela III apresenta os tamanhos dos cristalitos, obtidos pela equação de Debye-Scherrer. 


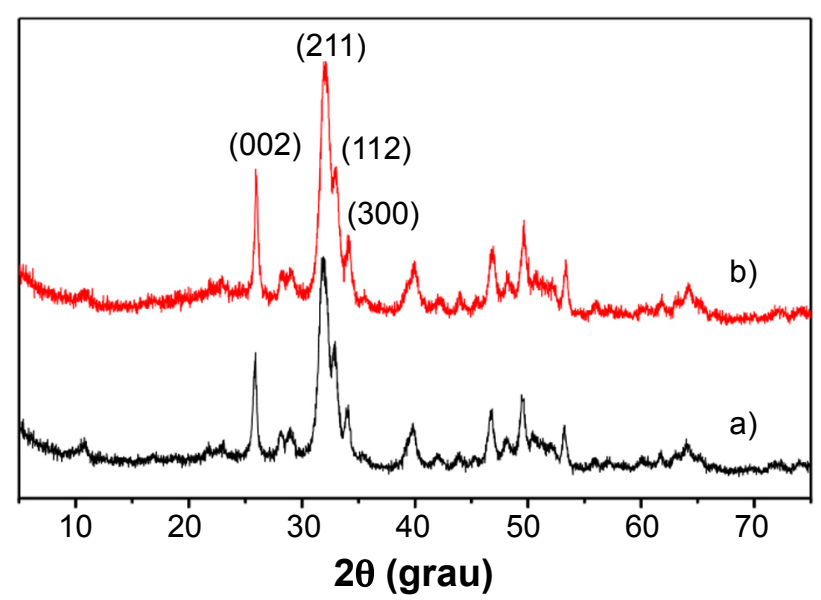

Figura 1: Difratogramas de raios X da HAp (a) e do biomaterial HAp/CHX10 (b).

[Figure 1: XRD patterns of HAp (a) and HAp/CHX10 biomaterial (b).]

Tabela II - Comparação entre as posições dos picos $(2 \theta)$ do arquivo cristalográfico de referência, da HAp e do HAp/ CHX.

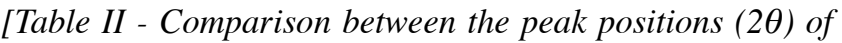
the reference crystal file, $\mathrm{HAp}$ and $\mathrm{HAp} / \mathrm{CHX}$.]

\begin{tabular}{ccc}
\hline JCPDS 00-003-0747 & HAp & HAp/CHX \\
\hline 25,87 & 25,92 & 25,99 \\
28,96 & 28,98 & 28,24 \\
32,05 & 32,06 & 31,89 \\
32,90 & 32,94 & 32,28 \\
34,06 & 34,08 & 34,08 \\
39,67 & 39,82 & 39,96 \\
49,49 & 49,42 & 49,53 \\
53,21 & 53,20 & 53,31 \\
64,17 & 64,10 & 64,02 \\
72,03 & 71,98 & 72,03 \\
\hline
\end{tabular}

Tabela III - Tamanho médios dos cristalitos. [Table III - Average crystal size.]

\begin{tabular}{ccc}
\hline Biomaterial & $\begin{array}{c}\text { Ângulo de } \\
\text { difração }\end{array}$ & $\begin{array}{c}\text { Tamanho do } \\
\text { cristalito (nm) }\end{array}$ \\
\hline HAp & 10,64 & 1,76 \\
HAp & 22,90 & 1,75 \\
HAp/CHX & 10,60 & 0,99 \\
HAp/CHX & 22,94 & 2,15 \\
\hline
\end{tabular}

Os espectros de FTIR da HAp pura, do biomaterial HAp/CHX10 e da CHX pura são mostrados na Fig. 2. Estes espectros mostram as diferenças e as especificidades que cada material apresentou. Ao se analisar o espectro da CHX, observou-se nitidamente uma banda larga na região entre 3700 e $2800 \mathrm{~cm}^{-1}$, que se referiu às vibrações de estiramento de grupos aminos $(\mathrm{N}-\mathrm{H})$ presentes na estrutura da $\mathrm{CHX}$, assim como da sobreposição da banda referente ao grupo hidroxila $(\mathrm{O}-\mathrm{H})$ referente à água, por estar em solução aquosa. Vibrações de $\mathrm{C}=\mathrm{C}$ dos anéis aromáticos e de $\mathrm{C}-\mathrm{H}$ que compõe a CHX também se apresentaram no espectro da CHX, porém apareceram sobrepostas nesta mesma região $[19,20]$. Na região compreendida entre 1630 e 1650 $\mathrm{cm}^{-1}$ pôde-se observar uma pequena banda correspondente à deformação angular simétrica do plano como também dobramentos dos grupos aminos e hidroxilas. Na região entre 1485 e $1445 \mathrm{~cm}^{-1}$ apareceram as bandas referentes à deformação de grupos $\mathrm{CH}_{2}$. Entre 1100 e $1000 \mathrm{~cm}^{-1}$ observaram-se as bandas referentes à vibração $\mathrm{Ar}-\mathrm{Cl}$ (cloro ligado ao anel aromático). Foi possível observar ainda bandas no espectro da $\mathrm{CHX}$ na região entre 800 e $850 \mathrm{~cm}^{-1}$ provenientes de anéis aromáticos para-dissubstituídos, que também se encontram presentes na estrutura da $\mathrm{CHX}$ [20, 21]. A análise do espectro de FTIR da HAp pura mostrou a presença de uma banda em $3400 \mathrm{~cm}^{-1}$ referente às vibrações de estiramento de grupos $\mathrm{OH}$ presentes na HAp como também a de grupos $\mathrm{OH}$ provenientes de água fissisorvida sobre a superfície do material. Uma banda na região entre 845 e $725 \mathrm{~cm}^{-1}$ foi relacionada ao estiramento do grupamento $\mathrm{P}-\mathrm{O}(\mathrm{H})$. A banda presente na região de $1050 \mathrm{~cm}^{-1}$ correspondeu à deformação assimétrica dos grupos fosfatos $\left(\mathrm{PO}_{4}{ }^{3-}\right)$. Sobre o fosfato também se pode destacar a banda em $611 \mathrm{~cm}^{-1}$ referente à deformação assimétrica P-O. Sobre o grupamento $\mathrm{P}-\mathrm{O}(\mathrm{H})$, verificou-se a presença de bandas em 566 e $470 \mathrm{~cm}^{-1}$ correspondendo à deformação assimétrica do grupamento $\mathrm{HPO}_{4}{ }^{2-}[21$, 22]. Ao se observar o espectro de FTIR do biomaterial (HAp/CHX), observou-se que possuiu características dos espectros de ambos precursores (HAp e CHX). Pode-se citar a banda na região de $1050 \mathrm{~cm}^{-1}$ que correspondeu à deformação assimétrica dos grupos fosfatos. Outra banda em comum com a da HAp pura que apareceu foi a da região entre 845 e $725 \mathrm{~cm}^{-1}$ proveniente do estiramento do grupamento $\mathrm{P}-\mathrm{O}(\mathrm{H})[21,22]$. Além dos pontos em comum, algumas modificações foram percebidas no espectro de FTIR do biomaterial, quando comparado ao espectro da HAp pura. A banda que se iniciou em $2960 \mathrm{~cm}^{-1}$ apresentou um alargamento em relação aos espectros dos dois materiais precursores. Esse fato se deve às interações dos grupos metilênicos $(\mathrm{C}-\mathrm{H})$ provenientes da $\mathrm{CHX}$ que foi incorporada com os grupos $\mathrm{OH}$ presentes na $\mathrm{HAp}$. Outra modificação que ocorreu foi o alargamento da banda na região de 1700 a $1550 \mathrm{~cm}^{-1}$, que se deve à deformação angular dos grupos aminos incorporados. Na região de $570 \mathrm{~cm}^{-1}$ também se observou um alargamento do pico de deformação dos grupos $\mathrm{P}-\mathrm{O}(\mathrm{H})$.

A Fig. 3 apresenta uma comparação entre os espectros de FTIR da HAp pura e dos biomateriais preparados com diferentes concentrações de $\mathrm{CHX}$. Pôde-se perceber que à medida que a concentração de $\mathrm{CHX}$ aumentou, regiões específicas dos espectros ficaram diferenciadas. Uma das diferenças ocorreu nas bandas da região entre 3685 e $2796 \mathrm{~cm}^{-1}$ e que se deve às interações dos estiramentos dos grupos $\mathrm{OH}$ presentes na HAp, dos grupos N-H e C-H da estrutura da CHX. A Tabela 


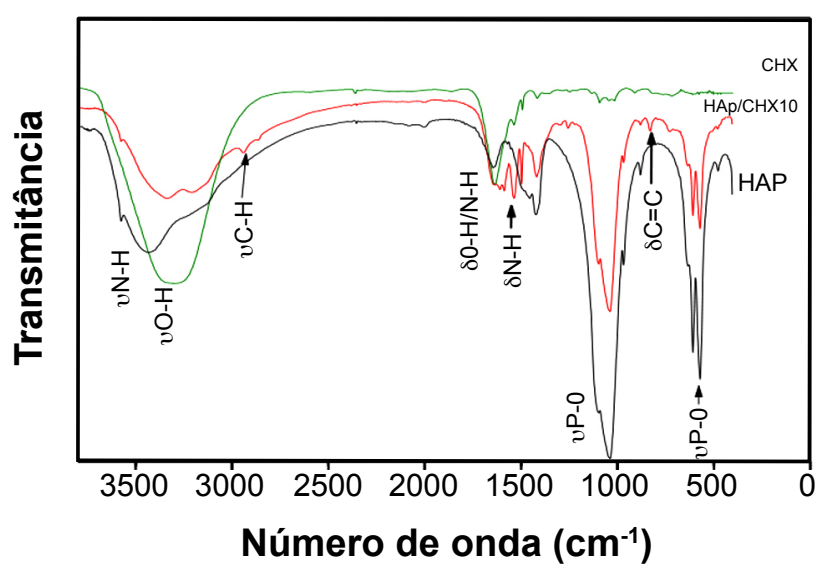

Figura 2: Espectros de FTIR da hidroxiapatita pura (HAp), do biomaterial (HAp/CHX10) e da clorexidina (CHX).

[Figure 2: FTIR spectra of pristine hydroxyapatite (HAp), biomaterial (HAp/CHX1O) and chlorhexidine (CHX).]

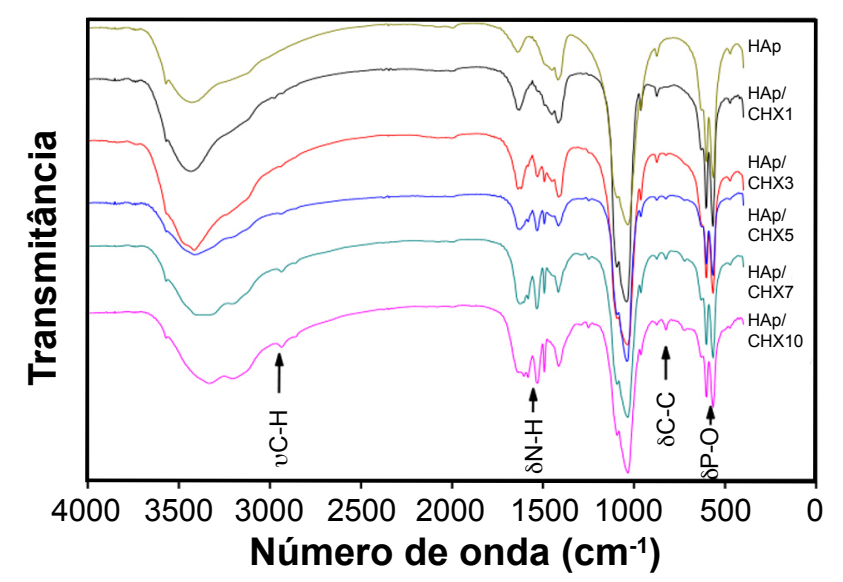

Figura 3: Espectros de FTIR da HAp pura e dos biomateriais com incorporação de CHX em diferentes proporções.

[Figure 3: FTIR spectra of pristine HAp and the biomaterials with CHX incorporation in different proportions.]
IV traz as atribuições das principais bandas de FTIR da $\mathrm{CHX}$, da HAp e do biomaterial HAp/CHX. Outra banda que se destacou foi a da região de 1690 a $1370 \mathrm{~cm}^{-1}$. Este alargamento se deve aos dobramentos dos grupos aminos que foram acrescidos com a incorporação da CHX. Outra peculiaridade que surgiu foi a intensificação da banda em $873 \mathrm{~cm}^{-1}$ referente aos dobramentos do grupo $\mathrm{C}=\mathrm{C}$ dos anéis aromáticos presentes na estrutura da $\mathrm{CHX}$.

As curvas de TG (termogravimetria) para a HAp, CHX e alguns biomateriais são apresentados na Fig. 4. A utilização dos dois materiais de partida, HAp e CHX, serviram de comparação para se observar o comportamento dos biomateriais. O biomaterial $\mathrm{HAp} / \mathrm{CHX} 3$ mostrou um comportamento de um biomaterial mais próximo da HAp. O biomaterial HAp/CHX7 apresentou um comportamento intermediário, mas já com indícios da $\mathrm{CHX}$ incorporada. O HAp/CHX10 teve o mesmo comportamento térmico do $\mathrm{HAp} / \mathrm{CHX} 7$, porém, devido à maior quantidade de $\mathrm{CHX}$ incorporada, apresentou maior perda de massa. Na curva de TG da HAp, constatou-se que a maior perda de massa ocorreu até $100{ }^{\circ} \mathrm{C}$, perda representada pela saída de água adsorvida fisicamente na superfície do material. Após $100{ }^{\circ} \mathrm{C}$ ainda foi possível se observar perda de massa, onde esse evento pode ser explicado pela perda de água a partir da condensação de grupos hidroxilas existentes na estrutura da hidroxiapatita, $\mathrm{Ca}_{10}\left(\mathrm{PO}_{4}\right)_{6}(\mathrm{OH})_{2}$, ocorrendo com mais ênfase a partir de $800{ }^{\circ} \mathrm{C}$ [23]. Já para a curva de TG da clorexidina, em temperatura inferior a $100{ }^{\circ} \mathrm{C}$, maior parte do solvente foi eliminada, com percentual de massa eliminada superior a $70 \%$, ocorrendo a eliminação total do solvente até $200{ }^{\circ} \mathrm{C}$, com perda de $80 \%$ em massa, devido a este fármaco ser comercializado em solução a $20 \%$ ( $80 \%$ restante é solvente), e a partir de $200{ }^{\circ} \mathrm{C}$ ocorreu a degradação da estrutura da clorexidina em dois diferentes eventos térmicos.

Para uma análise mais detalhada dos biomateriais preparados a partir da HAp com a incorporação da CHX

Tabela IV - Atribuição das bandas de FTIR presentes nos espectros da HAp, HAp/CHX e CHX.

[Table IV - Assignment of the FTIR bands present in the spectra of HAp, HAp/CHX and CHX.]

\begin{tabular}{cccc}
\hline Banda & $\mathrm{HAp}\left(\mathrm{cm}^{-1}\right)$ & $\mathrm{HAp} / \mathrm{CHX}\left(\mathrm{cm}^{-1}\right)$ & $\mathrm{CHX}\left(\mathrm{cm}^{-1}\right)$ \\
\hline vO-H & 3489 & 3344 & - \\
vN-H (grupo amino) & - & $3053-3575$ & $3720-2850$ \\
vC-H & - & 2931 & $3720-2850$ (sobreposta) \\
vP-O (grupo fosfato) & 1098 e 1049 & 1098 e 1039 & - \\
$v \mathrm{P}-\mathrm{O}(\mathrm{H})$ & 879 & 879 & - \\
$\delta \mathrm{O}-\mathrm{H}$ de $\mathrm{H}_{2} \mathrm{O}$ adsorvida & 1649 & $1660-1580$ & - \\
$\delta \mathrm{N}-\mathrm{H}$ & - & $1660-1580$ & 1639 \\
$\delta$ de grupos $\mathrm{C}=\mathrm{C}$ aromáticos & - & Sobreposta & - \\
$\delta \mathrm{O}-\mathrm{H}$ de $\mathrm{H}_{2} \mathrm{O}$ & 629 & 619 & - \\
$\delta \mathrm{P}-\mathrm{O}$ do grupo $\mathrm{PO}_{4}{ }^{3-}$ & 611 & 595 & - \\
$\delta \mathrm{P}-\mathrm{O}$ do grupo $\mathrm{HPO}_{4}^{2-}$ & 570 e 470 & 560 e 480 & \\
\hline
\end{tabular}




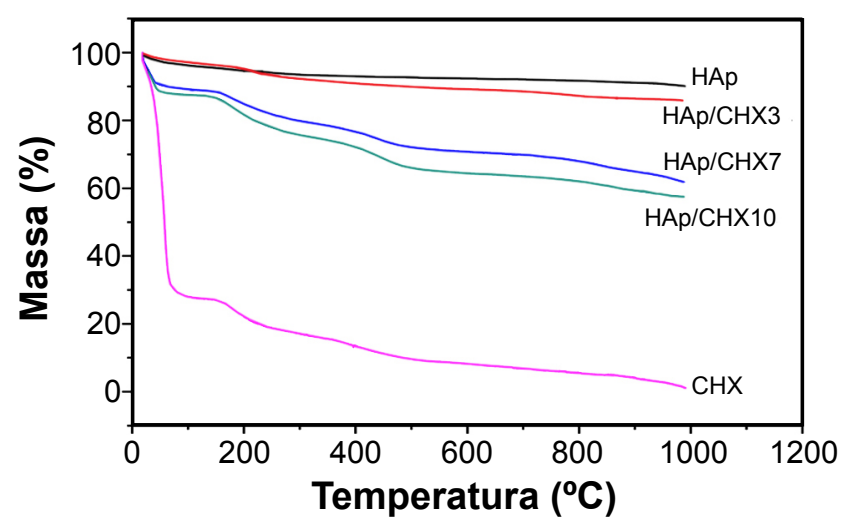

Figura 4: Curvas de TG da HAp pura e dos biomateriais. [Figure 4: TG curves of pristine HAp and biomaterials.]

a Fig. 5 mostra as curvas de TG e DTG do biomaterial HAp/CHX10. A curva DTG do biomaterial mostrou a ocorrência de 4 eventos. O primeiro evento foi relacionado à liberação da água fisicamente adsorvida e que ocorreu na faixa entre 27 e $123{ }^{\circ} \mathrm{C}$, caracterizando uma perda de $10,58 \%$ de massa. $\mathrm{O}$ segundo evento observado aconteceu na faixa de 123 a $320{ }^{\circ} \mathrm{C}$, correspondendo este evento à saída dos grupos externos da $\mathrm{CHX}$, possuindo uma perda de massa de aproximadamente $12,2 \%$, referente à primeira decomposição do fármaco [19, 24]. O terceiro evento ocorreu pela decomposição da $\mathrm{CHX}$ restante no biomaterial. Esta terceira decomposição ocorreu entre 320 e $600{ }^{\circ} \mathrm{C}$, que ocasionou uma perda de $10,73 \%$ de massa, referente à saída dos demais grupos referentes ao segundo evento de decomposição da clorexidina. O quarto evento foi atribuído à condensação de grupos hidroxilas com saída de água da HAp, que ocorreu na faixa de 600 até $991{ }^{\circ} \mathrm{C}$, com mais ênfase a partir de $800{ }^{\circ} \mathrm{C}$ [23] até a temperatura final do experimento. $\mathrm{O}$ valor da perda de massa desta última etapa foi em torno de $7 \%$.

As Figs. 6 e 7 apresentam os resultados da microscopia eletrônica de varredura e de transmissão para os biomateriais com e sem a presença de CHX. Por meio das imagens de MEV (Fig. 6) pôde-se observar a morfologia porosa da HAp, onde os poros se comportam como sítios que recebem e aglomeram as moléculas de

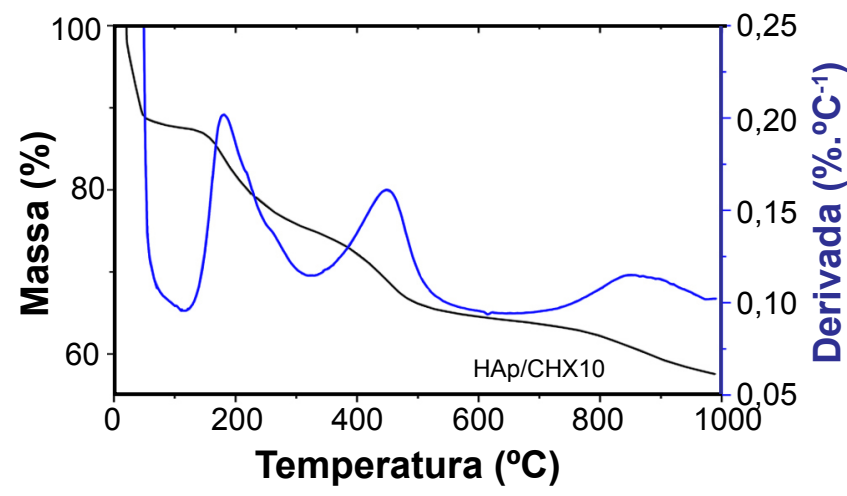

Figura 5: Curva TG/DTG do biomaterial HAp/CHX10. [Figure 5: TG/DTG curve of HAp/CHX10 biomaterial.]
CHX em sua superfície. As imagens de MET (Fig. 7) mostraram que os biomateriais possuíram partículas com morfologia cilíndricas com tamanhos variando na ordem de nanômetros.

Adsorção: a incorporação de CHX na HAp por interface sólido-líquido foi estudada pela curva de adsorção que é mostrada na Fig. 8. A isoterma mostrou os valores de CHX que foram incorporados na HAp. Foi observado que a solução mais diluída de CHX tinha concentração inicial de $0,2 \%$ e teve uma quantidade de $0,014 \mathrm{mg} / \mathrm{g}$ incorporada na HAp. A análise da curva de incorporação de CHX na HAp, combinada com os testes de atividade antimicrobiana, mostrou a quantidade necessária do fármaco para se atingir um efeito bactericida eficaz, ao tempo que se evita concentrações elevadas de CHX e desperdício de fármaco.

Testes microbiológicos: todos os biomateriais preparados tiveram sua atividade antimicrobiana testada contra as cepas Streptococcus mutans, Staphylococcus aureus e Escherichia coli. Dentre as diversas concentrações dos biomateriais preparados, cada bactéria apresentou uma resistência específica, necessitando concentrações diferentes de CHX
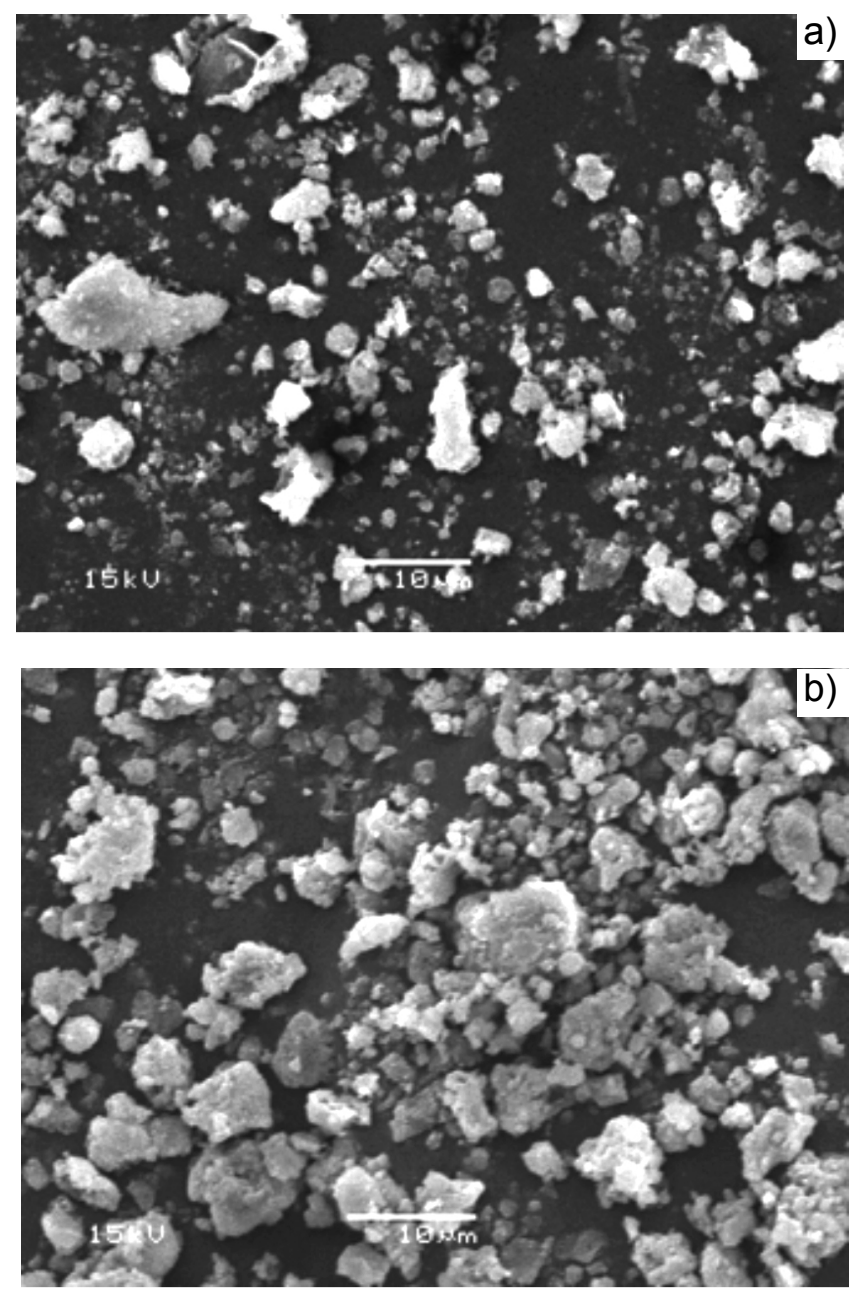

Figura 6: Imagens de MEV dos biomateriais: a) HAp; e b) HAp/ CHX.

[Figure 6: SEM images of the biomaterials: a) HAp; and b) HAp/ CHX.] 


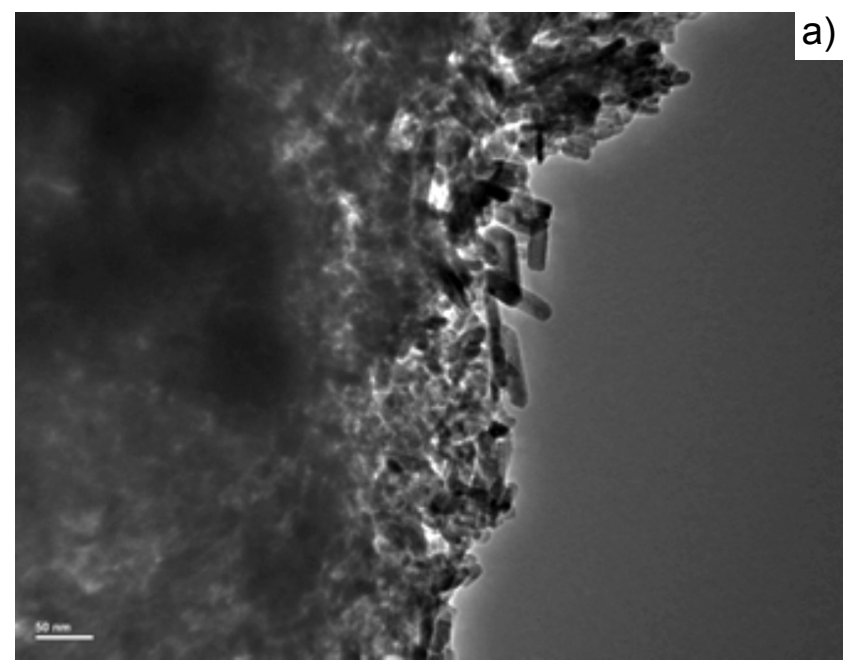

a)

Figura 7: Imagens de MET dos biomateriais: a) HAp; e b) HAp/CHX. [Figure 7: TEM images of the biomaterials: a) HAp; and b) HAp/CHX.]

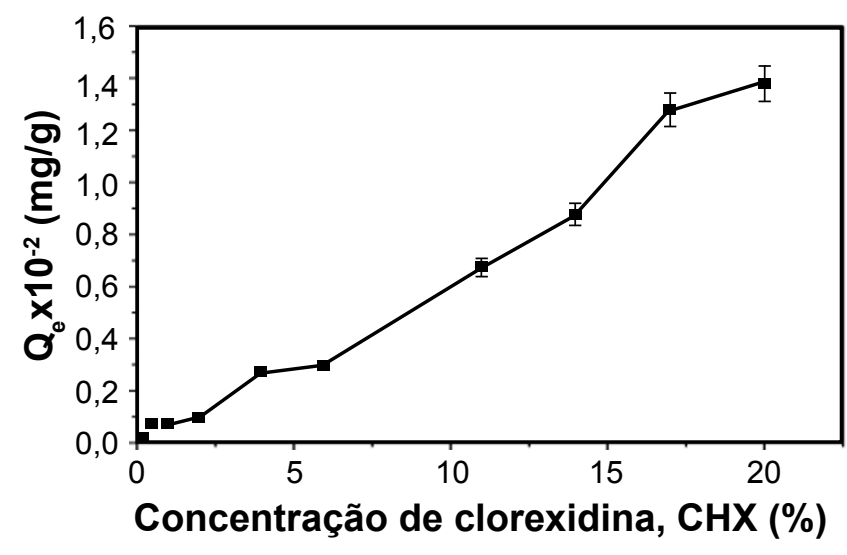

Figura 8: Isoterma de adsorção da CHX na superfície da HAp. [Figure 8: Adsorption isotherm of CHX on HAp surface.]

nos biomateriais para possuir efeito inibitório total. Os resultados do efeito inibitório para cada tipo de bactéria estão dispostos na Tabela VI. Os resultados mostraram que todos os biomateriais preparados apresentaram efeito inibitório contra as cepas bacterianas, porém nem todos

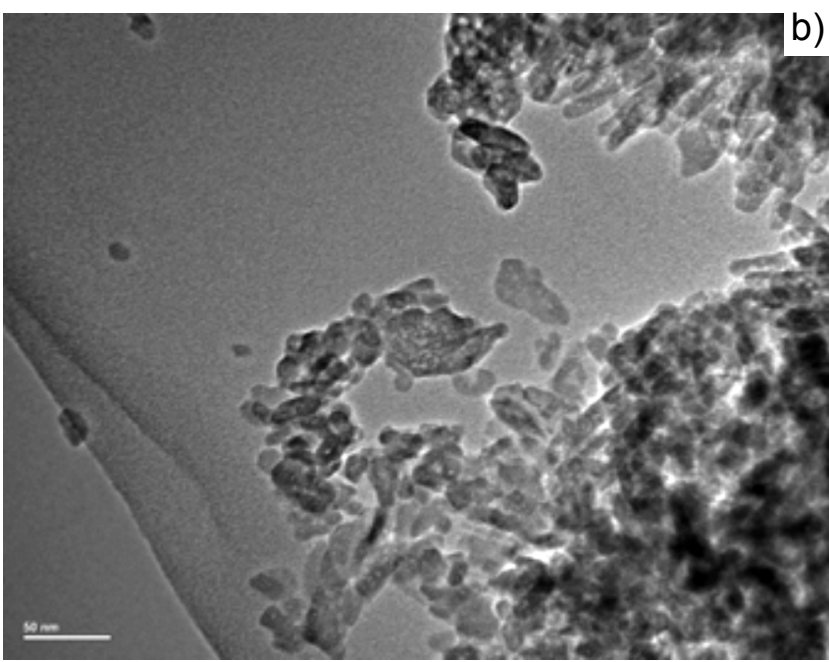

b)

tiveram a eficácia de $100 \%$. O biomaterial HAp/CHX1 com apenas 0,014 mg de CHX para cada grama de HAp mostrou um excelente efeito inibitório contra as cepas da Streptococcus mutans e da Escherichia coli, com efeitos inibitórios acima de $99 \%$ para estas bactérias, propriedade esta que a hidroxiapatita independente da rota de síntese não apresenta [25]. O efeito inibitório total contra os três tipos de bactérias ocorreu com o valor de $\mathrm{Q}_{\mathrm{e}}$ equivalente a 0,071 $\mathrm{mg}$ de $\mathrm{CHX} / \mathrm{g}$ de HAp, o que correspondeu ao biomaterial HAp/CHX3. Comercialmente o digluconato de clorexidina é fornecido em concentração em volume de $20 \%$, ao tempo em que o biomaterial $\mathrm{HAp} / \mathrm{CHX} 3$ teve sua síntese com uma solução de concentração em volume de apenas $1 \%$, mostrando-se eficaz na inibição de agentes patógenos de diversas áreas do corpo, entre elas a cavidade oral. Esse resultado mostrou como a CHX é utilizada em concentração elevada, ao tempo que o biomaterial conseguiu proporcionar uma ação bactericida eficaz mesmo com uma concentração menor em relação à clorexidina comercial. A Fig. 9 apresenta as imagens dos testes microbiológicos, resultado que corroborou a eficácia da ação antimicrobiana. De acordo com [26], a ação antimicrobiana da CHX é explicada pela

Tabela VI - Efeito inibitório apresentado pelos biomateriais HAp/CHX em diferentes concentrações contra as cepas de Streptococcus mutans, Staphylococcus aureus e Escherichia coli.

[Table VI - Inhibitory effect presented by HAp/CHX biomaterials in different concentrations against strains of Streptococcus mutans, Staphylococcus aureus and Escherichia coli.]

\begin{tabular}{cccc}
\hline Biomaterial & $\begin{array}{c}\text { Streptococcus mutans } \\
\text { (\% de inibição) }\end{array}$ & $\begin{array}{c}\text { Staphylococcus aureus } \\
\text { (\% de inibição) }\end{array}$ & $\begin{array}{c}\text { Escherichia coli } \\
\text { (\% de inibição) }\end{array}$ \\
\hline HAp/CHX1 & 99,7 & 88,2 & 99,1 \\
HAp/CHX2 & 100,0 & 93,7 & 100,0 \\
HAp/CHX3 & 100,0 & 100,0 & 100,0 \\
HAp/CHX4 & 100,0 & 100,0 & 100,0 \\
HAp/CHX5 & 100,0 & 100,0 & 100,0 \\
Salina fisiológica & - & - & - \\
\hline
\end{tabular}




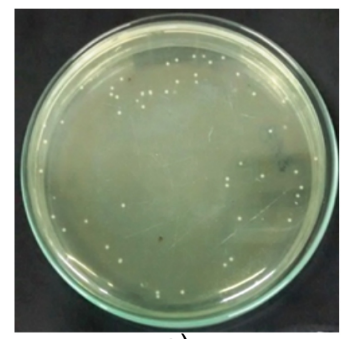

a)

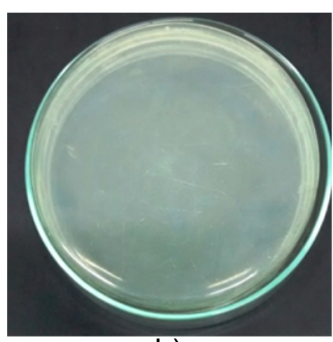

b)

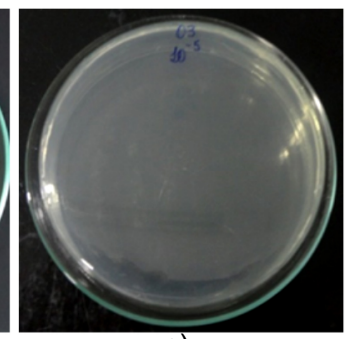

C)

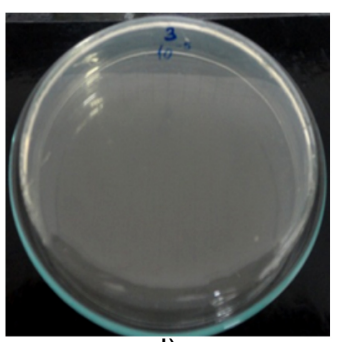

d)

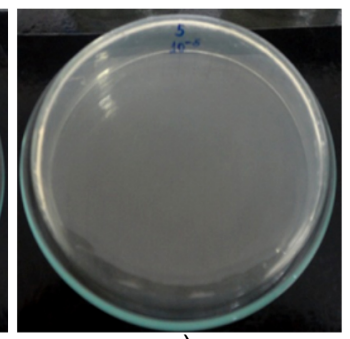

e)

Figura 9: Imagens de testes microbiológicos: a) controle positivo (solução salina); efeito inibitório dos biomateriais contra: b) Streptococcus mutans; c) Staphylococcus aureus; d) Escherichia coli; e e) controle positivo (solução de CHX).

[Figure 9: Images of microbiological tests: a) positive control (saline solution); inhibitory effect of the biomaterial against: b) Streptococcus mutans; c) Staphylococcus aureus; d) Escherichia coli; and e) positive control (CHX solution).]

interação entre os grupos catiônicos presentes na estrutura da CHX que são atraídos pela carga negativa da superfície bacteriana, fazendo que ocorram interações eletrostáticas, caracterizando-se pela adsorção da CHX na superfície da bactéria. A adsorção que ocorre provoca o rompimento, lise, da parede celular da bactéria ocasionando a sua morte [2629].

\section{CONCLUSÕES}

O estudo da incorporação da CHX pela HAp revelou a possibilidade da união de um material biocompatível com o tecido dentário do organismo humano a um fármaco bastante utilizado na prevenção de enfermidades periodontais. As técnicas DRX e FTIR confirmaram o sucesso da síntese da HAp, como também da incorporação da CHX no material como foi mostrado nos picos dos difratogramas e nas bandas encontradas nos espectros de FTIR. Os resultados de TG/ DTG corroboraram a incorporação da CHX na HAp. As microscopias, MEV/MET, desvendaram a morfologia do biomaterial sintetizado. Testes antimicrobianos de contato direto contra Streptococcus mutans, Staphylococcus aureus e Escherichia coli multirresistentes mostraram a eficácia de todos os biomateriais sintetizados frente a estes microrganismos, ressaltando que a quantidade de CHX que mostrou eficaz na ação antimicrobiana foi de $0,2 \%$, muito abaixo da encontrado comercialmente. Assim, desenvolveu-se um material com potencial de ser utilizado como enchimento de pequenas partes da arcada dentárias e maxilar.

\section{AGRADECIMENTOS}

\section{A CAPES, CNPQ, FAPEPI e UFPI.}

\section{REFERÊNCIAS}

[1] W.D. Callister Jr., D.G. Rethwisch, Ciência e engenharia de materiais: uma introdução, $8^{\mathrm{a}}$ ed., Rio de Janeiro (2013) 5.

[2] CGEE, "Materiais avançados no Brasil 2010-2022", Brasília (2010) 9.

[3] J.C. Elliot, in: Studies in inorganic chemistry, $2^{\mathrm{a}}$ ed.,
Elsevier (1994) 18.

[4] A.A. Campbell, Mater. Today 6, 11 (2003) 26.

[5] A.C. Guastaldi, A.H. Aparecida, Quím. Nova 33, 6 (2010) 1352.

[6] A.H. Aparecida, M.V.L. Fook, M.L. Santos, A.C. Gustaldi, Quím. Nova 30, 4 (2007) 892.

[7] L.L. Hench, J. Am. Ceram. Soc. 74 (1991) 1487.

[8] E. Kawachi, C.A. Bertran, R.R. Reis, O.L. Alves, Quím. Nova 23 (2000) 518.

[9] J. Huracek, P. Spirig, Arch. Orthop. Traum. Su. 113 (1994) 72 .

[10] P. Cheang, K.A. Khor, Biomaterials 17 (1996) 537.

[11] G.J. Tortora, B.R. Funke, C.L. Case, Microbiologia, 10 ${ }^{\mathrm{a}}$ ed., Artmed, Porto Alegre (2000) 184.

[12] L. Netuschil, T. Hoffmann, M. Brecx, Int. J. Dent. Hyg. 1, 3 (2003) 143.

[13] E. Akaki, “Avaliação da incorporação de agentes antibacterianos a cimentos resinosos", Tese Dr., UFMG (2005).

[14] K.I.R. Teixeira, "Estudo das alterações da membrana celular de microrganismos por compostos de inclusão de clorexidina: beta-ciclodextrina em diferentes proporções molares usando microscopia de força atômica e microscopia eletrônica de varredura", Diss. Mestr., UFMG (2008).

[15] Y.L. Zheng, F.J. Zhu, Carbohydr. Polym. 54 (2003) 527. [16] M. Solati-Hashjin, S.S. Shafiei, A. Goudarzi, R. Salarian, A. Nemati, Mater. Sci. Poland 27 (2009) 961.

[17] A. Kolodziejczak-Radzimska, M. Samuel, D. Paukszta, A. Pisecki, T. Jesionowski, Physicochem. Probl. Mi. 50, 1 (2014) 225.

[18] A.M. Sofronia, R. Baies, E.M. Anghel, C.A. Marinescu. S. Tanasescu, Mater. Sci. Eng. C 43 (2014) 153.

[19] I.O. Mazali, F.A. Sigoli, M. Strauss, D.C.F. Moreira, $34^{\mathrm{a}}$ Reun. An. Soc. Bras. Quím., Florianópolis (2011).

[20] D.L. Pavia, G.M. Lampman, G.S. Kriz, J.R. Vyvyan, Introdução à espectroscopia, $4^{\mathrm{a}}$ ed., Cengage Learning, S. Paulo (2010) 15.

[21] R.M. Silverstein, F.X. Webster, D.J. Kiemle, Identificação espectrométrica de compostos orgânicos, 7 ed., LTC, Rio de Janeiro (2006) 70.

[22] V. Ramakrisshhnan, V.U. Nayar, G. Aruldhas, Infrared Phys. 26, 6 (1986) 353.

[23] O.G. Silva, E.C. da Silva Filho, M.G. da Fonseca, 
L.N.H. Arakaki, C. Airoldi, J. Colloid Interface Sci. 302 (2006) 485.

[24] E. Adolfsson, M. Nygren, L, Hermansson, J. Am. Ceram. Soc. 82, 1 (1999) 2909.

[25] G.T. Feitosa, M.V.B. Santos, H.M. Barreto, L.C.N. Nunes, J.A. Osajima, E.C. da Silva Filho, Mater. Sci. Forum 869 (2016) 890.
[26] G. Rölla, B. Melsen, J. Dent. Res. 54 B (1975) 57.

[27] L.G. Hjeljord, G. Rölla, P. Bonesvoll, J. Period. Res. Suppl. 12 (1973) 1.

[28] D. Voet, J.G. Voet, Bioquímica, $3^{\text {a }}$ ed., Artmed, Porto Alegre (2006) 374.

[29] M.J. Winrow, J. Period. Res. Suppl. 12 (1973) 45. (Rec.03/11/2017, Rev.07/02/2018, 28/08/2018, 09/10/2018, Ac. 19/10/2018) 